\title{
Weight before and after a diagnosis of breast cancer or ductal carcinoma in situ: a national Australian survey
}

\author{
Carolyn Ee ${ }^{1 *} \mathbb{D}$, Adele Elizabeth Cave ${ }^{1}$, Dhevaksha Naidoo ${ }^{1}$, Kellie Bilinski $^{1}$ and John Boyages ${ }^{2}$
}

\begin{abstract}
Background: Overweight/obesity are strongly implicated in breast cancer development, and weight gain postdiagnosis is associated with greater morbidity and all-cause mortality. The aim of this study was to describe the prevalence of overweight/obesity and the pattern of weight gain after diagnosis of breast cancer amongst Australian women.
\end{abstract}

Methods: We collected sociodemographic, medical, weight and lifestyle data using an anonymous, selfadministered online cross-sectional survey between November 2017 and January 2018 from women with breast cancer living in Australia. The sample consisted mainly of members of the Breast Cancer Network Australia Review and Survey Group.

Results: From 309 responses we obtained complete pre/post diagnosis weight data in 277 women, and calculated pre/post Body Mass Index (BMI) for 270 women. The proportion of women with overweight/obesity rose from $48.5 \%$ at diagnosis to $67.4 \%$ at time of survey. Most women were Caucasian with stage I-III breast cancer $(n=254)$ or ductal carcinoma in situ (DCIS) $(n=33)$ and mean age was 59.1 years. The majority of women $(63.7 \%)$ reported they had gained weight after diagnosis with an average increase of $9.07 \mathrm{~kg}$ in this group. Of the women who provided complete weight data, half gained $5 \mathrm{~kg}$ or more, $17.0 \%$ gained $>20 \mathrm{~kg}$, and $60.7 \%$ experienced an increase in BMl of $>1 \mathrm{~kg} / \mathrm{m}^{2}$. Over half of the women rated their concern about weight as high. Of those women who gained weight, more than half reported that this occurred during the first year after diagnosis. Two-thirds (69.1\%) of women aged 35-74 years gained, on average, $0.48 \mathrm{~kg}$ more weight per year than age-matched controls.

Conclusions: Although the findings from this survey should be interpreted cautiously due to a limited response rate and self-report nature, they suggest that women in Australia gain a considerable amount of weight after a diagnosis of breast cancer/DCIS (in excess of age-matched data for weight gain) and report high levels of concern about their weight. Because weight gain after breast cancer may lead to poorer outcomes, efforts to prevent and manage weight gain must be prioritized and accelerated particularly in the first year after diagnosis.

Keywords: Breast cancer, DCIS, Overweight, Obesity, Weight gain, Australian women, National survey, Prevalence

\footnotetext{
* Correspondence: c.ee@westernsydney.edu.au

'NICM Health Research Institute, Western Sydney University, Locked Bag

1797, Penrith, NSW 2751, Australia

Full list of author information is available at the end of the article
}

(c) The Author(s). 2020 Open Access This article is distributed under the terms of the Creative Commons Attribution 4.0 International License (http://creativecommons.org/licenses/by/4.0/), which permits unrestricted use, distribution, and reproduction in any medium, provided you give appropriate credit to the original author(s) and the source, provide a link to the Creative Commons license, and indicate if changes were made. The Creative Commons Public Domain Dedication waiver (http://creativecommons.org/publicdomain/zero/1.0/) applies to the data made available in this article, unless otherwise stated. 


\section{Background}

Breast cancer is the most common cancer in women worldwide and in Australia [1-3]. There were over 2 million new cases of breast cancer (BC) globally in 2018, with this figure expected to rise to over 3 million by 2040 [3], by which time Australia expects to diagnose more than 25,000 new cases annually [2]. Obesity is a known risk factor for BC, particularly for postmenopausal women [4]. Obesity after menopause (from weight gain during either the premenopausal or postmenopausal years) is directly related to an increased relative risk of $\mathrm{BC}$ of 1.11 per $5 \mathrm{~kg}$ increase in weight [5].

Obesity at diagnosis is associated with worse BC survival and all-cause mortality rates and may increase the risk of cancer recurrence by $30-40 \%[1,6]$. Furthermore, weight gain is common after $\mathrm{BC}$ diagnosis, and may increase the risk of disease recurrence and mortality and have a negative impact on quality of life [1]. Weight gain after $\mathrm{BC}$ diagnosis is thought to be multifactorial and may be related to the use of systemic treatment, younger age at diagnosis, as well as changes in lifestyle [1, 7]. Given the growing population of BC survivors and the link between weight gain and adverse health outcomes, research into weight after $\mathrm{BC}$ is of critical importance.

The prevalence of weight gain after $\mathrm{BC}$ in Australia has not been adequately quantified. One prospective cohort study conducted in Queensland, in women who had been diagnosed with early breast cancer, described an increase in the proportion of women who were overweight/obese from $57 \%$ at diagnosis to $68 \%$ over 6 years [8]. However, there is no national data currently available and few population studies exist [9]. The aim of this study was to describe the prevalence of self-reported overweight and obesity before and after a diagnosis of BC or Ductal Carcinoma in Situ (DCIS).

\section{Methods}

\section{Study design and inclusion criteria}

A cross-sectional self-administered anonymous survey was conducted in Australia between November 2017 and January 2018 using Qualtrics ${ }^{\oplus}$ online survey software [10]. Any woman living in Australia who self-identified as having $\mathrm{BC}$ was eligible to complete the survey. A copy of the Participant Information Sheet was provided electronically via a link on the survey website prior to starting the survey, and women were informed that consent was implied upon commencing the survey. This method of consent was approved by the Human Research Ethics Committee (See below for details). The sample included members of the Breast Cancer Network Australia (BCNA) Review and Survey Group comprising BCNA members who had agreed to receive emails about research studies. Limiting research at BCNA to the Review and Survey group allows researchers to access women who are engaged in the research process, while protecting other BCNA members from frequent research requests. The Review and Survey Group $(n=1857)$ represents approximately $2 \%$ of all BCNA members and is one of the largest breast cancer consumer groups available for research in Australia, representing an important source of feedback for the research community.

The survey was emailed to 1835 members on December 5th, 2017 and a reminder email sent January 15th, 2018 (Appendix). A smaller sample $(n=26)$ was also drawn from online communities (women's health organization social media pages and online breast cancer support groups in Australia) or through word of mouth during November and December 2017. Ethics approval for this study was provided by the Human Research Ethics Committee, Western Sydney University (H12444, October 2017).

\section{Survey instrument}

The survey was developed after reviewing previous literature on weight after $\mathrm{BC}$ and was subsequently revised to include feedback from six BCNA representatives and several health researchers. The 60-item survey included questions on the sociodemographic characteristics, medical details such as diagnosis and treatment, lifestyle habits, weight status, and weight management. Details of the survey questions are outlined in the Appendix. In this paper, we report on change in weight from time of diagnosis to time of the survey.

\section{Weight after diagnosis}

Women were asked to self-report their weight in $\mathrm{kg}$ at the time of diagnosis, and current weight and height (in meters). Body Mass Index (BMI) was calculated from weight and height as weight/height ${ }^{2}$. The pattern of weight since diagnosis was also assessed as "gained weight overall", "lost weight overall", "weight stable" or "weight has fluctuated a great deal". We devised an unvalidated 11-point Likert scale to evaluate concern about weight (using the question "Please rate how concerned you have been over your weight in the last 12 months") ranging from 0 (not at all concerned) to 10 (very concerned). We further characterized these data into four categories according to the Likert score: No concern (0), A little concerned (1-3), Somewhat concerned (4-7), Very concerned (8-10). Weight at diagnosis was reported by $90 \%$ of total respondents ( 277 women) and current weight by $95 \%$ of respondents ( 293 women).

\section{Statistical analysis}

IBM SPSS $^{\oplus}$ statistics package version 23 [11] and Stata statistical software version 13.11 [12] were used to analyze the data presented in this report. We used descriptive statistics to analyze diagnoses, treatments 
received, and health provider visits of respondents in percentages. Women who did not self-report their weight were excluded from analyses relating to weight. We calculated the percentage of women who were currently overweight (BMI $\geq 25$ and $<30$ ) or obese $(B M I \geq 30)$ and compared this to the proportion who were overweight/obese at time of diagnosis. Current and pre-cancer weight and BMI were reported as a mean and standard deviation. We calculated the number and percentage of women whose BMI changed from healthy $(<25)$ to unhealthy $(\mathrm{BMI} \geq 25)$ from diagnosis to time of survey, as well as women who reported an increase of BMI of greater than $1 \mathrm{~kg} / \mathrm{m}^{2}$. Tests for skewness and kurtosis for weight, BMI at diagnosis, current weight and BMI, and weight gain, indicated that our data had a normal distribution.

We described the self-reported weight gain pattern as percentage of body weight at diagnosis, the proportion of women who gained $>5 \mathrm{~kg}$, and the proportion of women who gained $5-10 \%$ and $>10 \%$ of body weight. We used a paired t-test to compare weight and BMI at diagnosis and weight and BMI at time of survey, and Fisher's exact test to explore the association between current BMI classification and weight concern. To test the relationship between weight gain and time since diagnosis (and therefore the hypothesis that weight gain increases with time) we performed a Pearson's correlation. We also categorized time since diagnosis into 2.5 year blocks and ran a one-way analysis of variance (ANOVA) exploring the relationship between time since diagnosis and weight gain in the following groups of women: women who reported gaining weight overall, and who had self-reported weight gain $>5 \%$. We explored the relationship between amount of weight gain and weight gain concern using the Pearson's chi-squared test.

We calculated the mean weight gain per year in our sample as total weight gain divided by time since diagnosis in years. We removed one outlier who reported gaining $10.5 \mathrm{~kg}$ per year over 2 years and reported rate of weight gain across age groups in five-year brackets (see Fig. 3 and Table 5).

\section{Comparing rate of weight gain against normative data}

To compare weight gain in our sample against normative data in the Australian population, we used data the AusDiab study. The AusDiab study is a large national, longitudinal population-based study involving $>11,000$ adults aged 25 years and older. Baseline data collection for the AusDiab study occurred during 1999-2000, with a subsequent 5-year follow-up (during 2004-2005) [13]. The AusDiab study reported the following mean weight gains per year at 5-year follow-up (2004-5): $700 \mathrm{~g}$ per year for $25-34 y o, 500 \mathrm{~g}$ for $35-44 y o, 380 \mathrm{~g}$ for $45-54 y o$,
$140 \mathrm{~g}$ for 55-64yo and $0 \mathrm{~g}$ for 65-74yo). For each respondent in our study for which we could calculate a yearly weight gain, we compared this weight gain with the mean weight gain from AusDiab corresponding to the age group of the respondent by subtracting the AusDiab weight gain from the weight gain reported by that respondent in our study. We used Pearson's chi-squared testing to compare the numbers of women who gained in excess of the rates reported in the AusDiab study across the age groups described above.

\section{Results}

\section{Survey response}

Of the 1857 BCNA members, $283(15 \%)$ responded to the survey. A further 26 women responded to the survey from other channels giving a total of 309 responses.

\section{Sample characteristics}

Demographic characteristics of respondents are described in Table 1 . The majority of women were Caucasian $(92.5 \%, n=285)$ with a mean age of 59.1 years $(S D=9.5$, range $33-78, n=298)$. Characteristics were similar across BCNA members and non-BCNA respondents with no differences between these groups on Pearson's Chi-squared test. The majority of women were either premenopausal (43\%) or perimenopausal $(12 \%)$ at the time of diagnosis. Of the 145 women who were still menstruating at time of diagnosis, $68 \%$ were premenopausal and became postmenopausal, $18 \%$ were perimenopausal and became postmenopausal, while a smaller number (13\%) remained perimenopausal.

\section{Clinical characteristics \\ Diagnoses}

Clinical diagnoses of the respondents are summarized in Table 2. The majority of women $(82 \%, n=252)$ had been diagnosed with non-metastatic $\mathrm{BC}$. The mean time since diagnosis of $\mathrm{BC}$ was 8.2 years (SD 5.12, range $1-32$ years) and mean age at diagnosis was 50.9 years $(\mathrm{SD}=9.02$, range $29-74$ ).

\section{Treatments}

Women reported receiving a range of $\mathrm{BC}$ treatments including surgery and/or radiation, and axillary, systemic and hormonal treatments, which are detailed in Table 2. The most commonly visited health care providers, within the last 12 months, were breast surgeons ( $n=$ $172)$, physiotherapists $(n=124)$ and medical oncologists (for chemotherapy) $(n=119)$. On average, respondents $(n=247)$ had visited three health care providers in the last 12 months (range, 1-10). For women with DCIS, 18 (53\%) had a mastectomy, 17 (50\%) had received radiation and 19 (56\%) had received hormonal treatment. 
Table 1 Demographic characteristics of survey respondents

\begin{tabular}{|c|c|c|}
\hline Description & $\begin{array}{l}\mathrm{N} \\
\text { (responses) }\end{array}$ & $\%$ \\
\hline \multicolumn{3}{|l|}{ State $(n=309)$} \\
\hline Australian Capital Territory & 14 & $4.5 \%$ \\
\hline New South Wales & 91 & $29.5 \%$ \\
\hline Northern Territory & 0 & $0.0 \%$ \\
\hline Queensland & 48 & $15.5 \%$ \\
\hline South Australia & 28 & $9.1 \%$ \\
\hline Tasmania & $<5$ & $1.0 \%$ \\
\hline Victoria & 95 & $30.7 \%$ \\
\hline Western Australia & 30 & $9.7 \%$ \\
\hline \multicolumn{3}{|l|}{ Education $(n=307)$} \\
\hline High school- year 10 & 30 & $9.8 \%$ \\
\hline High school- year 12 & 35 & $11.4 \%$ \\
\hline Vocational College & 55 & $17.9 \%$ \\
\hline Bachelor's degree & 90 & $29.3 \%$ \\
\hline Postgraduate degree & 97 & $31.6 \%$ \\
\hline \multicolumn{3}{|l|}{ Ethnicity $(n=308)$} \\
\hline European/Anglo Saxon/Caucasian & 285 & $92.5 \%$ \\
\hline Asian & 5 & $1.6 \%$ \\
\hline $\begin{array}{l}\text { Oceanic (incl. Australian and New Zealand first } \\
\text { peoples, Polynesian and Micronesian) }\end{array}$ & 13 & $4.2 \%$ \\
\hline North/South/Central American & $<5$ & $0.7 \%$ \\
\hline Mixed ethnicity & $<5$ & $0.7 \%$ \\
\hline Indian & $<5$ & $0.3 \%$ \\
\hline \multicolumn{3}{|l|}{ Employment $(n=308)$} \\
\hline Employee & 140 & $45.5 \%$ \\
\hline Self-employed & 33 & $10.7 \%$ \\
\hline Home duties/caring for children or family & 15 & $4.9 \%$ \\
\hline In education (going to school, university, etc.) & $<5$ & $1.3 \%$ \\
\hline Doing voluntary work & 10 & $3.3 \%$ \\
\hline Unable to work because of illness & 6 & $2.0 \%$ \\
\hline Unable to work for other reasons & $<5$ & $0.3 \%$ \\
\hline Retired & 99 & $32.1 \%$ \\
\hline \multicolumn{3}{|l|}{ Relationship Status ( $n=309$ ) } \\
\hline Single & 39 & $12.6 \%$ \\
\hline Married/de facto (living with partner) & 230 & $74.4 \%$ \\
\hline In a relationship (not living with partner) & 7 & $2.3 \%$ \\
\hline Divorced/separated & 24 & $7.8 \%$ \\
\hline Widowed & 9 & $2.9 \%$ \\
\hline
\end{tabular}

\section{Weight change}

Table 3 and Fig. 1 describe weight and BMI change patterns in our respondents. Mean self-reported weight at time of diagnosis was $71.24 \mathrm{~kg}$ (SD 14.01, range $47-158, n=277)$ and at time of survey was $76.08 \mathrm{~kg}$ (SD 15.37, range 46-150, $n=293$ ). Mean
Table 2 Diagnoses and treatments received

\begin{tabular}{lllc}
\hline Description & $\mathrm{N}$ & $\%$ & Missing $\mathrm{n}(\%)$ \\
\hline Diagnoses & & & $1(0.3 \%)$ \\
Ductal Carcinoma In Situ (DCIS) & 33 & $10.7 \%$ & \\
Localised breast cancer & 252 & $81.8 \%$ & \\
Metastatic breast cancer & 14 & $4.6 \%$ & \\
Inflammatory breast cancer & $<5$ & $0.7 \%$ & \\
Other including second primary & 7 & $2.3 \%$ & \\
Treatment to the Breast & & & $2(0.6 \%)$ \\
Lumpectomy alone & $<5$ & $0.7 \%$ & \\
Lumpectomy and radiation & 129 & $42.0 \%$ & \\
Mastectomy alone & 74 & $24.1 \%$ & \\
Mastectomy and radiation & 71 & $23.1 \%$ & \\
Lumpectomy and mastectomy alone & 10 & $3.3 \%$ & \\
Lumpectomy, mastectomy and radiation & 16 & $5.2 \%$ & \\
Double mastectomy & 5 & $1.6 \%$ & \\
Reconstruction after mastectomy (n=164) & & & \\
No & 84 & $51.2 \%$ & \\
Immediate & 37 & $22.6 \%$ & \\
Delayed & 43 & $26.2 \%$ &
\end{tabular}

Treatment to the Axilla $(n=167)$

$13(7.8 \%)$

Sentinel node biopsy only $\quad 24 \quad 15.6 \%$

Axillary dissection +/- Sentinel node $\quad 56 \quad 36.4 \%$

biopsy

Axillary dissection +/- Sentinel node $\quad 72 \quad 46.8 \%$

biopsy + radiation

Radiation only

$<5 \quad 1.3 \%$

Intravenous Systemic Therapy

Chemotherapy without Herceptin $\quad 164$ 53.1\%

Herceptin only $\quad<5 \quad 0.7 \%$

Chemotherapy + Herceptin $\quad 46 \quad 14.9 \%$

None/not reported $\quad 97 \quad 31.4 \%$

Hormonal Treatments

$\begin{array}{lll}\text { Tamoxifen alone } & 58 & 18.8 \%\end{array}$

Other $\quad 146 \quad 47.3 \%$

None $105 \quad 34.0 \%$

Current use of hormone therapy

$\begin{array}{lll}\text { Yes } & 125 \quad 40.5 \%\end{array}$

self-reported current BMI was $28.02 \mathrm{~kg} / \mathrm{m}^{2}(\mathrm{SD}=5.88$, $n=285)$ and mean pre-cancer BMI was $26.37 \mathrm{~kg} / \mathrm{m}^{2}$ $(\mathrm{SD}=5.92, n=271)$. Just under half of women $(48.5 \%)$ were overweight or obese at time of diagnosis, but by the time of the survey this proportion had risen to $67.3 \%$. This increase was most marked for women who were obese, from $17.0 \%$ at diagnosis to $31.9 \%$ at the time of the survey. Mean weight gain was $4.50 \mathrm{~kg}$ (SD 8.90, $n=277$ ). 
Table 3 Weight change patterns after diagnosis of breast cancer

\begin{tabular}{|c|c|c|c|c|}
\hline \multirow{3}{*}{ Self-reported weight gain pattern } & \multirow[t]{2}{*}{ Description } & \multirow[t]{2}{*}{$\mathrm{N}$} & \multirow[t]{2}{*}{$\%$} & \multirow{2}{*}{$\begin{array}{l}\text { Missing } \\
\text { N (\%) }\end{array}$} \\
\hline & & & & \\
\hline & & & & $17(5.5 \%)$ \\
\hline & Weight gain & 186 & $63.7 \%$ & \\
\hline & Weight loss & 38 & $13.0 \%$ & \\
\hline & Stable & 48 & $16.4 \%$ & \\
\hline & Fluctuated & 20 & $6.9 \%$ & \\
\hline \multirow[t]{5}{*}{ Calculated $\%$ weight change from baseline } & & & & $32(10.4 \%)$ \\
\hline & Weight loss & 62 & $22.4 \%$ & \\
\hline & $<5 \%$ weight gain & 53 & $19.1 \%$ & \\
\hline & $5-10 \%$ weight gain & 64 & $23.1 \%$ & \\
\hline & $>10 \%$ weight gain & 98 & $35.4 \%$ & \\
\hline \multirow[t]{6}{*}{ Calculated weight change } & & & & $32(10.4 \%)$ \\
\hline & Weight loss & 62 & $22.4 \%$ & \\
\hline & Weight gain up to $5 \mathrm{~kg}$ & 75 & $27.1 \%$ & \\
\hline & Weight gain $\geq 5 \mathrm{~kg}$ and $<10 \mathrm{~kg}$ & 75 & $27.1 \%$ & \\
\hline & Weight gain $\geq 10 \mathrm{~kg}$ and $<20 \mathrm{~kg}$ & 18 & $6.5 \%$ & \\
\hline & Weight gain $\geq 20 \mathrm{~kg}$ & 47 & $17.0 \%$ & \\
\hline \multicolumn{5}{|l|}{ Timing of weight gain ${ }^{a}(n=186)$} \\
\hline & $<6$ months post diagnosis & 47 & $25.3 \%$ & \\
\hline & $6-12$ months post diagnosis & 60 & $32.3 \%$ & \\
\hline & 12-18 months post diagnosis & 38 & $20.4 \%$ & \\
\hline & 18-24 months post diagnosis & 16 & $8.6 \%$ & \\
\hline & $2-3$ years post diagnosis & 14 & $7.5 \%$ & \\
\hline & $>3$ years post diagnosis & 11 & $5.9 \%$ & \\
\hline \multicolumn{5}{|c|}{ Change in BMI classification from time of diagnosis to time of survey $(n=270)$} \\
\hline \multirow[t]{5}{*}{ Weight gain } & Healthy to overweight & 49 & $18.2 \%$ & \\
\hline & Overweight to obese & 40 & $14.8 \%$ & \\
\hline & Healthy to obese & 5 & $1.9 \%$ & \\
\hline & Underweight to healthy weight & $<5$ & $1.5 \%$ & \\
\hline & Underweight to overweight & $<5$ & $0.4 \%$ & \\
\hline \multirow[t]{4}{*}{ Stable } & Remained in healthy range & 69 & $25.6 \%$ & \\
\hline & Remained in overweight range & 39 & $14.4 \%$ & \\
\hline & Remained in obese range & 40 & $14.8 \%$ & \\
\hline & Remained in underweight range & 8 & $3.0 \%$ & \\
\hline \multirow[t]{4}{*}{ Weight loss } & Healthy weight to underweight & 3 & $1.1 \%$ & \\
\hline & Obese or overweight to healthy weight & 6 & $2.2 \%$ & \\
\hline & Overweight to underweight & $<5$ & $0.4 \%$ & \\
\hline & Obese to overweight & 5 & $1.9 \%$ & \\
\hline
\end{tabular}

${ }^{a}$ this question was answered only if respondents had selected "gained weight overall"; BMl=Body Mass Index; Underweight $=\mathrm{BMI}<20 ; \mathrm{Healthy}$ weight $=\mathrm{BMI} \geq 20$ and $<25$; Overweight $=\mathrm{BMI} \geq 25$ and $<30$; Obese $=\mathrm{BMI} \geq 30$

One fifth (54/270, 20.0\%) of women went from being in the healthy weight range at diagnosis $(\mathrm{BMI}<25)$, to an unhealthy weight range (BMI $\geq 25$ ), a further $14.8 \%$ moved from the overweight range into obesity, and $60.7 \%(164 / 270)$ of women reported an increase in BMI greater than $1 \mathrm{~kg} / \mathrm{m} 2$ (Table 3). Of note, a small proportion of women lost weight whereby $5.6 \%$ of women went down at least one BMI category (Table 3).

There was a statistically significant difference between both weight and BMI at diagnosis and current weight 


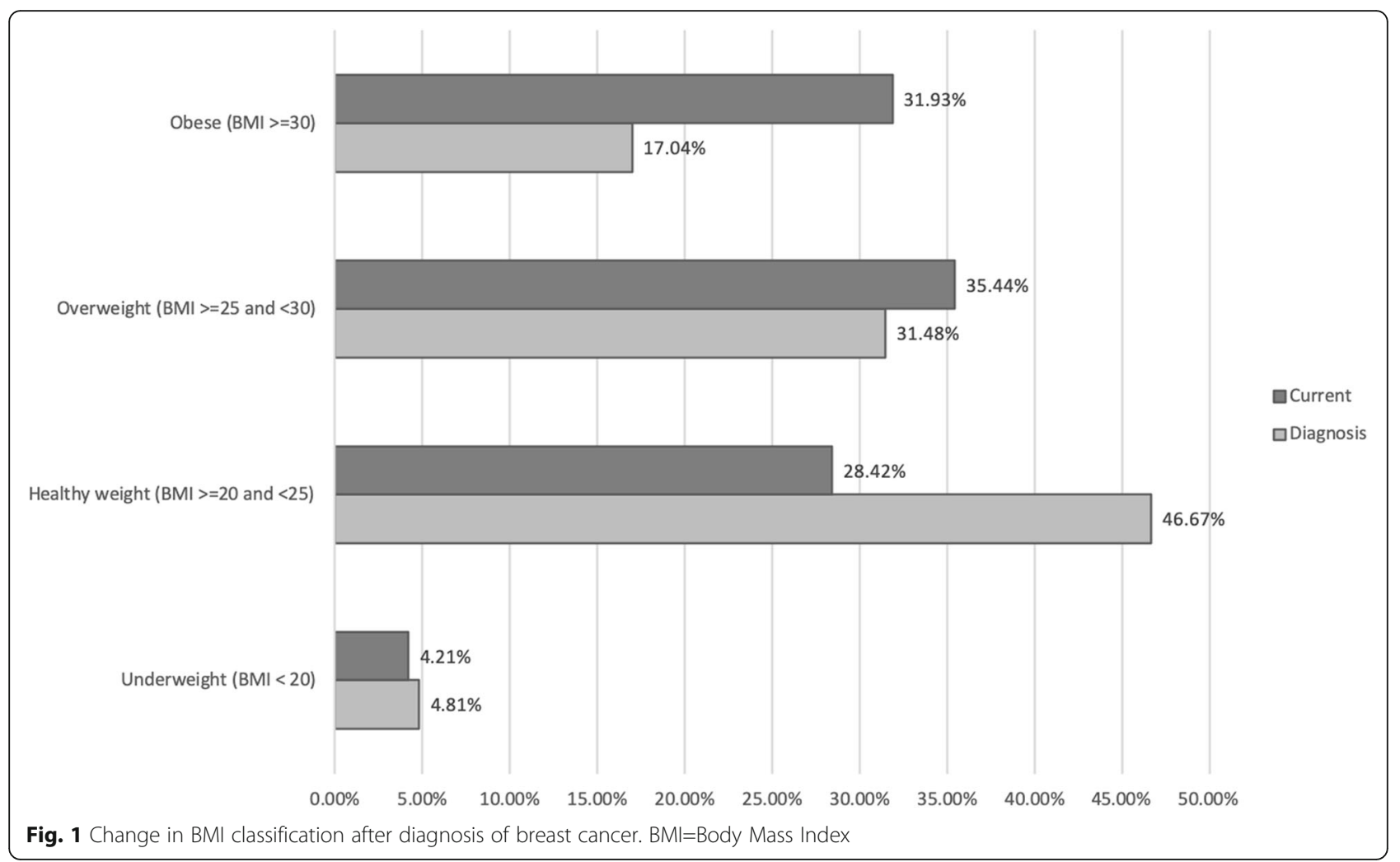

and BMI (mean difference $4.50 \mathrm{~kg}$, CI $3.45-5.55$, $p=0.00, n=277$ and $1.64 \mathrm{~kg} / \mathrm{m}^{2}$, CI $1.24-2.04, p=0.00$, $n=270$ respectively). The majority of respondents (63.7\%) reported they had gained weight overall after diagnosis. This is consistent with the self-reported weight gain in our study, where $58.5 \%$ of women gained $>5 \%$ of pre-diagnosis body weight. Half of the respondents had gained more than $5 \mathrm{~kg}$, with $17.0 \%$ reporting gains of over $20 \mathrm{~kg}$ of weight.

Of the women who reported gaining weight overall and for whom we had complete weight data $(n=175)$, $87.4 \%(153 / 175)$ gained $\geq 5 \mathrm{~kg}$ of weight, and $54.9 \%$ gained $>10 \%$ of pre-diagnosis body weight. Average weight gain in this group was $9.07 \mathrm{~kg}$. Women reported that weight gain predominantly occurred within the first
2 years of diagnosis (86.6\%) with $57.5 \%$ reporting that weight gain mostly occured within the first 12 months. Weight gain was not correlated with time since diagnosis ( $n=173, r=.114, p=0.14$ ). There was no difference in the amount of weight gain by time since diagnosis when this was examined in blocks of 2.5 years, in women who had reported weight gain overall $(n=175, p=0.26)$, and in women who self-reported weight gain of greater than $5 \%$ of diagnosis body weight $(n=162, p=0.27)$. (Table 4).

Three quarters $(74.7 \%, n=68 / 91)$ of women who were currently obese reported very high levels of concern about their weight, compared to a quarter of women in the healthy weight range $(25.9 \%, n=21 / 81)$ $(p=0.00)$. Women who had gained more weight were more likely to express high levels of concern about

Table 4 Weight gain by time in years since diagnosis

\begin{tabular}{|c|c|c|c|c|c|c|}
\hline & \multicolumn{3}{|c|}{ Women who had gained $>5 \%$ weight $(n=162)$} & \multicolumn{3}{|c|}{ Women who reported weight gain pattern overall $(n=175)$} \\
\hline & Mean weight gain $(\mathrm{kg})$ & SD & Freq. & Mean weight gain $(\mathrm{kg})$ & SD & Freq. \\
\hline \multicolumn{7}{|c|}{ Time since diagnosis (years) } \\
\hline$<2.5$ & 9.00 & $(6.51)$ & 6 & 8.14 & $(6.36)$ & 7 \\
\hline $2.5-5$ & 8.42 & $(4.57)$ & 23 & 7.36 & $(4.73)$ & 28 \\
\hline $5-7.5$ & 9.27 & $(5.27)$ & 54 & 8.90 & $(5.47)$ & 56 \\
\hline $7.5-10$ & 9.15 & $(5.42)$ & 22 & 8.43 & (5.64) & 24 \\
\hline$>10$ & 11.21 & (7.14) & 57 & 10.38 & (7.37) & 60 \\
\hline
\end{tabular}

SD Standard Deviation, Freq Frequency 
their weight. Of the women who gained $5-10 \%$ of weight and $>10 \%$ of weight, 54.8 and $78.4 \%$ reported being very concerned about their weight respectively, compared with $22.5 \%$ of women who had gained less than $5 \%$ of their diagnosis weight $\left(X^{2},(9, n=263)=\right.$ 67.6137, $p=0.000$ ). (Fig. 2).

\section{Rate of weight gain, and comparison with normative data} On average, women in our study gained $0.64 \mathrm{~kg}$ per year $(n=270, \mathrm{SD}=1.76$, range -8 to 10.5$)$ (see Table 5). For women aged 25-74 years (the age range for which we have normative data), the mean weight gain in excess of age-matched controls was $0.48 \mathrm{~kg}$ per year $(n=235, \mathrm{SD}=$ 1.67 , range -8.38 to 7.62$)$. Overall, two thirds $(69.8 \%)$ of women in our sample gained in excess of normative weight gain in the AusDiab study, including 25.1\% of women who gained $>1 \mathrm{~kg}$ per year in excess of normative rates of weight gain. There was no difference between age groups with regard to the number of women who gained in excess of normative weight gain $(X 2),(n=$ $235)=6.6929, p=0.153)$. See Fig. 3 for mean weight gain in excess of normative data for each age group. There was only one woman in the 25-34 age group; to protect confidentiality we did not include her data in Table 5 or Fig. 3.

\section{Discussion}

This is the first national survey conducted in Australia to describe weight after breast cancer. The distribution of responses according to state and territory in our survey is broadly consistent with the incidence of $\mathrm{BC}$ in these regions [14] indicating our sample was nationally representative by location. We found that two-thirds of our respondents were currently overweight or obese, with the majority of women reporting they had gained weight after diagnosis, mostly within the first 12 months and at a substantial self-reported average of $9.07 \mathrm{~kg}$. Of note, the proportion of women who were overweight or obese rose sharply from $48 \%$ at time of diagnosis to $67 \%$ at the time of the survey, with the proportion of women who were obese almost doubling from 17 to $32 \%$. The majority of women gained weight in excess of the rates reported in age-matched controls without breast cancer. This equated to an average of an additional $2.42 \mathrm{~kg}$ over 5 years. A very small proportion of women (5.6\%) changed from a higher to lower BMI category. It would be of interest to explore such findings to enquire whether this is a result of intended weight loss or treatment related effects.

The proportion of women who were overweight or obese in our study is consistent with those from a prospective study of 287 women conducted in Queensland, Australia which compared weight gain after diagnosis of

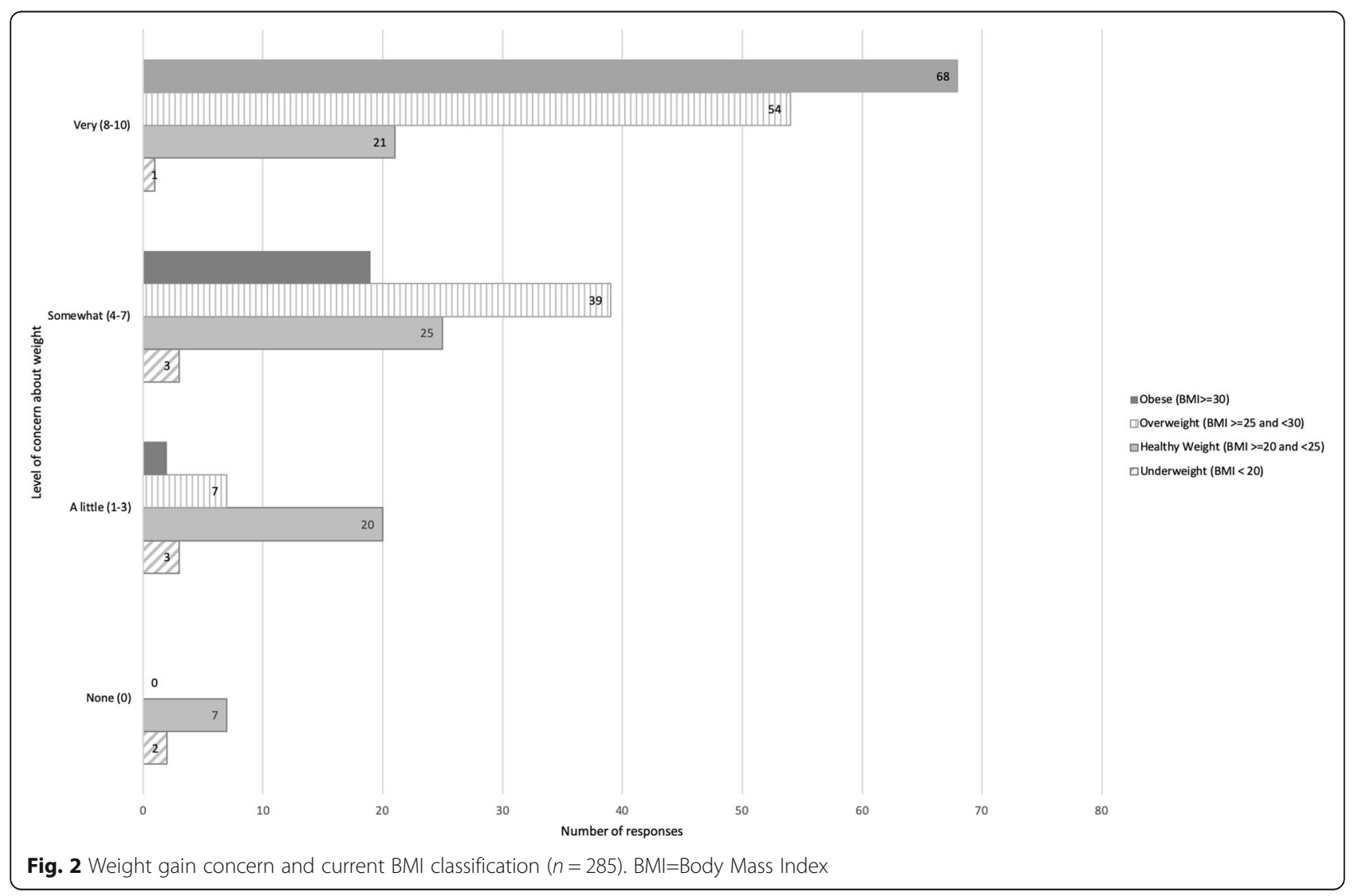


Table 5 Mean weight gain per year in each age group, and proportion who gained in excessive of normative rates

\begin{tabular}{lll}
\hline Age (years) & $\begin{array}{l}\text { Mean weight gain per year } \\
\text { in kg in our study (SD) }\end{array}$ & $\begin{array}{l}\text { \% who gained in excess } \\
\text { of AusDiab data }\end{array}$ \\
\hline $35-44(n=21)$ & $1.59(1.16)$ & 81.0 \\
$45-54(n=72)$ & $0.75(2.35)$ & 61.1 \\
$55-64(n=100)$ & $0.50(1.47)$ & 76.0 \\
$65-74(n=42)$ & $0.39(0.94)$ & 64.3 \\
All $(n=235)$ & $0.64(1.76)$ & 69.8 \\
\hline
\end{tabular}

early BC. By 6 years, $68 \%$ of women in the cohort were overweight or obese, [8] which is remarkably similar to our findings. Median weight gain for study participants between 6 and 72 months was $0.7 \mathrm{~kg}$, and mean BMI increase was $0.2 \mathrm{~kg} / \mathrm{m}^{2}$. The authors of the cohort study compared the weight gain in the $\mathrm{BC}$ cohort with agematched controls and reported a significant difference, with only $50 \%$ of age-matched controls being overweight or obese. One other population study has been published from Shanghai on obesity and clinical outcomes of 4561 Chinese women [9]. In that study, mean weight gain at 18 months post-diagnosis was $1.7 \mathrm{~kg}$. Mean weight gain in our study was significantly higher at 4.5 $\mathrm{kg}$ which could be explained by the longer time since diagnosis in our study. Further, the mean weight gain in women who had gained weight overall in our study is substantially higher than what is reported in the Australian cohort study $(9.07 \mathrm{~kg}$ vs $5.3 \mathrm{~kg}$ ) although we note that the mean time since diagnosis in our study is 8.2 years, while the cohort study used a 6-year follow-up. Our study provides additional data on weight gain after $\mathrm{BC}$ in Australia, over a wider time frame and location and with a larger sample size, and suggests that the problem of weight gain after $\mathrm{BC}$ may be larger than previously anticipated.

A large international review found that $50-96 \%$ of early stage $\mathrm{BC}$ patients experience weight gain during treatment in the range of $1.7 \mathrm{~kg}$ to $5.0 \mathrm{~kg}$ in the 18 months following treatment [15]. Of those who gained weight, $27 \%$ gained $2 \mathrm{~kg}$ to $5 \mathrm{~kg}$ and $24 \%$ gain $5 \mathrm{~kg}$ or more in the 18 months following treatment. This compares to our study where $50.55 \%$ reported gaining $5 \mathrm{~kg}$ or more mainly in the first 18 months after treatment, again suggesting that weight gain after $\mathrm{BC}$ is a greater problem than previously thought.

Our findings are of concern because weight gain preand post- $\mathrm{BC}$ diagnosis have both been associated with increased morbidity and mortality. Whilst those at heaviest weight at diagnosis appear to carry an increased risk, even those within the healthy weight range at diagnosis face increased risk following weight gain [16]. Data from the Nurse's Health Study in the USA showed the risk of cancer recurrence was increased by $40 \%$ following a mean weight gain of $2.7 \mathrm{~kg}$, and by $53 \%$ following mean weight gain of $7.7 \mathrm{~kg}$, [17] with the greatest increased risk in those of healthy weight at diagnosis. Another observational study of 3993 women, each $5 \mathrm{~kg}$ gain in weight post-diagnosis was associated with a significant $12 \%$ increase in all-cause mortality, $13 \%$ increase in BCspecific mortality, and $19 \%$ increase in cardiovasculardisease mortality (all $p<0.05$ ) after an average 6.3 years follow-up after diagnosis [18]. Extrapolating from these results indicate that approximately half of our cohort face a significant increase in cancer recurrence and mortality due to weight gain $>5 \mathrm{~kg}$, and that efforts to prevent weight gain in women diagnosed with $\mathrm{BC}$ need to be accelerated and prioritized.

Our findings indicate high levels of concern about weight, particularly in women who were currently overweight or obese. Weight gain exacerbates the significant body image concerns already faced by BC survivors, has a negative impact on quality of life, and may be a cause of distress if it was unanticipated [19]. We did not explore quality of life or levels of distress in our cohort, but additional research in this area appears to be warranted.

Although the proportion of overweight and obesity in our survey is similar to national data for women aged 45-64 (which ranges from 61 to 69\%) [20], the majority of our respondents were from a higher socioeconomic group with $60 \%$ having a Bachelor's degree qualification or higher, and $56 \%$ being employed or self-employed. National data indicate rates of overweight and obesity for women in the highest socioeconomic group as low as $48 \%$ [20] indicating that the proportion of overweight and obesity in our respondents is higher than would be expected of women with similar demographic characteristics. Finally, when compared to age-matched controls from the AusDiab study, $69.8 \%$ of women in our survey gained in excess of normative weight gain, indicating that the weight gain experienced within our sample is unlikely to be explained by weight gain that would normally be experienced as women age and progress through the menopausal transition.

This study also highlights the importance of treatment teams being aware that weight gain, particularly in the first year after treatment, is an important issue, which would benefit from interventions such as diet and exercise. In this study, 186 of 292 patients (63.69\%) gained weight, $57 \%$ gained within the first 12 months and $77 \%$ within 18 months. The timing of weight gain within the first year of treatment has been reported by others [21, 22]. Recently, the Clinical Oncological Society of Australia has strongly advocated for exercise to be embedded as part of standard practice in cancer care and advised all members of the multidisciplinary cancer team to promote physical activity, encourage patients to 


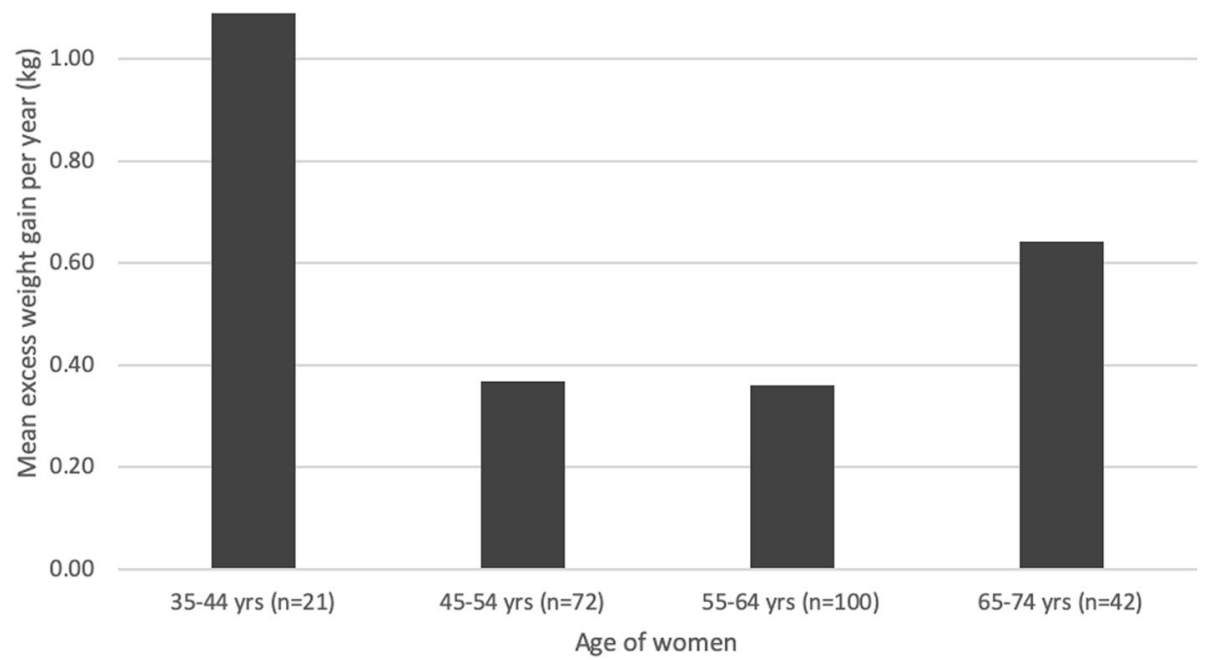

Fig. 3 Mean weight gain per year in excess of normative data, by age $(n=234)$

adhere to exercise guidelines and refer patients to an accredited exercise physiologist or physiotherapist with experience in cancer care [23]. All people with cancer should progress towards and, once achieved, maintain participation in at least $150 \mathrm{~min}$ of moderate intensity or $75 \mathrm{~min}$ of vigorous-intensity aerobic exercise (e.g. walking, jogging, cycling, swimming) each week; and two to three resistance exercise (i.e. lifting weights) sessions each week involving moderate-to-vigorous-intensity exercises targeting the major muscle groups. In women with breast cancer, there appears to be a window of opportunity within the first 18 months to initiate weight management interventions in order to prevent excessive weight gain.

Strengths of this survey include the higher than expected response rate from the BCNA Review and Survey Group. According to the Research and Evaluation Manager, BCNA (email communication 3 Oct 2017), the typical response rate in this group is $10 \%$, whereas the response to our survey was $15 \%$. However, given that the Review and Survey Group represents only approximately $2 \%$ of all BCNA members, the validity of our findings is somewhat limited but important to highlight particularly to clinicians managing patients with breast cancer to ensure they encourage and more importantly "prescribe" an exercise program after cancer treatment.

We achieved a broadly nationally representative sample according to location. The percentage of respondents from each Australian State and Territory is similar to national averages on $\mathrm{BC}$ incidence as described by the Australian Institute of Health and Welfare cancer data [14].

Limitations of this survey included its self-report nature. In general, people tend to underestimate their weight and overestimate their height with self-reporting [24]. Social desirability bias and response bias may play a part in this inaccuracy. In our cross-sectional study, it is possible that recall bias led to further underestimation of pre-diagnosis weight, therefore inflating the reported weight gain. Additionally, a small proportion of women chose not to report their weight in this survey (10\% for pre-diagnosis weight, and $5 \%$ for current weight). However, using self-reported weight and height is simple and readily accessible, and is considered less intrusive than objectively measured weight, therefore allowing us to conduct a nation-wide survey and increase the response rate. The true prevalence of weight gain after $\mathrm{BC}$ may be different to that found in our survey as women who had gained weight after $\mathrm{BC}$ may have been more likely to respond to our survey compared to women who had not gained weight. Nevertheless, the prevalence reported in our survey is remarkably similar to that in prospective cohort studies, suggesting that our data is robust. There is an urgent need to further understand the predictors of weight gain in women with BC. Further planned analyses from our data will include analysis of the predictors of weight gain in our sample, including use of chemotherapy, hormonal therapy, and menopausal stage at diagnosis.

We acknowledge that the inability to provide matched controls in this survey is a limitation. However, we were able to retrospectively match women by age to controls from the 2005 AusDiab study and found that women gained in excess of normative data, although limitations of our comparison is that we could not locate more recent data on normative rates of weight gain, and the duration of weight gain varied in our sample. Furthermore, that our findings are remarkably similar to a 
cohort study in the state of Queensland in Australia [8] we believe our findings are a reliable representation of breast cancer survivors. Additionally, it would be of interest to look at change in weight over time and according to menopausal status in matched controls. As such this will be examined in a future manuscript.

We were unable to report on the proportion of fat mass gained relative to muscle mass lost, know as sarcopenia. Sarcopenia is common in many women even without body weight change, with $74 \%$ of women increasing total body fat relative to lean muscle, [25] with an increased risk from tamoxifen use [26] and common after reduced activity during chemotherapy. Such changes are associated with the development of comorbidities such as diabetes and cardiovascular disease, thereby influencing long-term survival [27]. Excess adiposity is also associated with poorer prognosis through increases in adipose derived circulating estrogens and via increased circulating levels of insulin, insulin-like growth factor and leptin [28].

Another potential weakness of our study is that the vast majority of survey respondents were Caucasian, thereby limiting the generalizability of our data to women from other ethnicities but provides an important perspective over and above the Shanghai study where patients were less overweight or obese at diagnosis and whose diet differed from a Western diet. Previous research from the United States, has shown when compared with non-Hispanic whites, Hispanic and black women have higher rates of obesity $(21.8 \%$, compared with 29.4 and $39.2 \%$, respectively), lower rates of meeting physical activity guidelines (19.0\%, compared with 12.5 and $17.5 \%$, respectively), and lower intake of three or more servings of fruit and vegetables per day $(27.7 \%$, compared with 19.7 and $21.9 \%$, respectively). Understanding this in the Australian context will be an important component of future research [29].

Additionally, although the response rate from the BCNA Review and Survey Group was higher than what is typically seen, this represented a very small proportion of all BCNA members, limiting the validity of our findings. Notwithstanding such limitations, the demographics in our sample (who were predominantly welleducated and either employed or self-employed) are not inconsistent with national data indicating that the incidence of breast cancer is highest in the areas with highest socioeconomic advantage [30]. Additionally, the demographics of the BCNA respondents and non-BCNA respondents were similar, suggesting that our findings can be extrapolated to other BCNA members.

\section{Conclusion}

This is the first national survey of Australian women to describe weight gain after diagnosis of BC. Survey respondents gained a subtantial amount of weight (mean of $9.07 \mathrm{~kg}$ ), with a doubling of the proportion of women living with obesity. This is coupled with high rates of concern about weight after breast cancer. Given that weight gain after BC may lead to poorer outcomes, there is a need to prioritize and accelerate efforts to assist women to prevent and manage weight gain after $\mathrm{BC}$, particularly during the first 12 months after diagnosis.

\section{Appendix \\ Specific demographic, medical, menopausal and lymphoedema details requested in the survey Demographic characteristics.}

State of residence, highest level of education, ethnicity, employment status, relationship status, current age and age at diagnosis were included to describe the characteristics of women.

\section{Medical details.}

Women were asked about their diagnosis, treatments received including treatments received to the axilla, the number of lymph nodes removed, whether they had a reconstruction, use of hormonal treatments, menopausal state (at diagnosis and current), presence of other medical conditions and symptoms such as hot flushes and the presence and severity of lymphoedema.

Women were asked to describe the type of breast cancer they were diagnosed with as either "ductal cancer insitu (DCIS)", "localised stage breast cancer (where your breast cancer is contained within your breast and/or lymph nodes), "metastatic breast cancer (breast cancer that has spread beyond the breast tissue and lymph nodes to distant parts of the body, such as the bones, liver and lungs; also called advanced, secondary or stage four) " or "inflammatory breast cancer. "For convenience, inflammatory breast cancer and metastatic breast cancer were then combined and referred to as advanced breast cancer. Women were also asked to indicate the treatments they received such as "Lumpectomy alone", "Lumpectomy and radiation", "mastectomy alone", "mastectomy and radiation", "removal of lymph nodes", "chemotherapy", "hormonal therapy", "targeted therapy (Herceptin)", and "other". As chemotherapy is invariably not provided to women with DCIS, we recoded the diagnosis as "localised" if a woman indicated that she had received chemotherapy.

Menopausal state at the time of diagnosis was assessed as either "Premenopausal (regular periods with no menopausal symptoms such as hot flushes)", "Perimenopausal/in the menopausal transition (no periods for at least 2 months, plus hot flushes)", "Postmenopausal (no periods for at least 12 months)" or "Previous surgical menopausal (both ovaries or uterus/womb had been removed)." Participants who indicated they were premenopausal or perimenopausal at the time of diagnosis were 
asked if they were having periods before breast cancer treatment and to describe what has happened to their periods now; "they have stopped", "they stopped and then started again", "they have become more irregular", "no change" or "other".

Lymphoedema severity was defined as either "no problem (no noticeable swelling)", "mild (soft swelling that is not obvious to others and comes and goes)", "moderate (swelling with occasional hardness in some areas that is obvious to others and is always present)", "severe (profuse swelling with thickened skin, constant hardness, and a very large, heavy arm that is extremely obvious to others and is always present) as described elsewhere [7]."

\section{Lifestyle habits.}

Women were asked if they had tried the following specific diets in the previous 12 months: Atkins diet (low carbohydrate), 5:2 diet (eat what you want 5 days a week, send your body into starvation mode for 2 days), Paleolithic diet, Dukan diet (High-protein, low-carb), Vegetarian diet, Vegan diet, Weight Watchers diet, Raw food diet, Ultra low-fat diet, Zon diet, Cambridge diet (very low calories), South Beach diet (low-GI), Other. They were asked if they ate at least the recommended serves of fruit and vegetables a day (2 fruit, five vegetable) with answer options of Yes/No. Self-perceived diet quality was assessed as Excellent/Very Good/Good/Fair/ Poor. Smoking was assessed as current cigarrete use (Never smoked/Ex smoker/Recently quit ex smoker (smoked in the last 3 months)/Current smoker) and current smokers were asked to indicate the number of cigarettes they smoked each day. Alcohol intake was assessed as Non drinker/1-7 standard drinks a week/814 standard drinks a week/>14 standard drinks a week) and a guide to standard drink sizes was provided. The validated Weight Self Efficacy Scale (WEL-SF) [3] was used to evaluate how confident women now felt about being able to successfully resist the desire to overeat in eight different situations on an 11-point Likert scale from 0 (not confident at all) to 10 (very confident). We further dichotomised the responses into "Not confident" (0-4) and "Confident" (5-10). Physical activity levels were calculated according to the number of 20-min sessions of less vigorous exercise or more vigorous exercise a week, given a weighting and described in terms of MET (metabolic cost) minutes where MET minutes less than 80 were coded as no physical activity, 80 to 400 as low, 400 to 560 as moderate and more than 560 as high. A value of 4 METs was given to moderate physical activity and 7.5 to vigorous physical activity [26].

\section{Weight management.}

Experiences with a range of weight loss interventions (Exercise, Diet - various: Intermittent fasting, etc. (please specify), Meal replacements e.g. shakes, Medication, Weight loss supplements/products, Surgery (please specify), Online program e.g. 12 week Body Transformation, Social support, Weight loss program e.g. Jenny Craig, Psychological treatments such as CBT (Cognitive Behavioural Therapy) and the perceived effectiveness of the interventions on was described using a five-point Likert scale from 1 (not at all effective) to 5 (very effective). The responses were further dichotomized into 1 to 2 (not effective) and 3 to 5 (effective). Women were also asked about perceived barriers and facilitators to successful weight loss and weight maintenance, and what they believed should be research priorities in this area.

\section{Abbreviations}

BC: Breast Cancer; BCNA: Breast Cancer Network Australia; BMI: Body Mass Index; DCIS: Ductal Carcinoma In Situ; GP: General Practitioner

\section{Acknowledgements}

We thank the consumer representatives from Breast Cancer Network Australia who provided feedback on the survey instrument used in this study; Natalie Zakhary who assisted with formatting the online survey and Karen Monaghan who assisted with data cleaning.

Participants in this research were recruited from Breast Cancer Network Australia's (BCNA) Review and Survey Group, a national, online group of Australian women living with breast cancer who are interested in receiving invitations to participate in research. We acknowledge the contribution of the women involved in the Review and Survey Group who participated in this project. Part of this manuscript has previously been presented at the Australian New Zealand Obesity Society/Australasian Society for Lifestyle medicine and International Chair on Cardiometabolic Risk (ANZOS-ASLMICCR) Annual Scientific Meeting in 2019 (http://anzos-aslm-iccr-2019.p. asnevents.com.au/days/2019-10-18/abstract/65217).

\section{Authors' contributions}

CE conceived of the study, designed the survey instrument, and collected the data. JB and KB contributed to design of the survey instrument and study. AEC led the data analysis. DN contributed significantly to

interpretation of the data, drafting of the manuscript, and critical revision for important intellectual content. CE, AEC, JB, KB and DN contributed significantly to the interpretation of the data, drafting the manuscript, critical revision of the manuscript for important intellectual content, and provided final approval for publication.

\section{Funding}

This study did not receive any funding. CE is supported by an endowment from the Jacka Foundation of Natural Therapies.

\section{Availability of data and materials}

The datasets used and/or analysed during the current study are available from the corresponding author on reasonable request.

\section{Ethics approval and consent to participate}

Consent was implied upon commencing the online anonymous survey. Ethics approval was provided by the Human Research Ethics Committee, Western Sydney University (H12444, Oct 2017).

\section{Consent for publication}

Not applicable.

\section{Competing interests}

The authors declare that they have no competing interests.

\section{Author details}

${ }^{1}$ NICM Health Research Institute, Western Sydney University, Locked Bag 1797, Penrith, NSW 2751, Australia. ${ }^{2}$ ICON Cancer Centre, Sydney Adventist Hospital, Wahroonga, NSW 2076, Australia. 
Received: 25 July 2019 Accepted: 21 January 2020

Published online: 20 February 2020

\section{References}

1. Vance V, Mourtzakis M, McCargar L, Hanning R. Weight gain in breast cancer survivors: prevalence, pattern and health consequences. Obes Rev. 2011:12(4):282-94

2. Cancer compendium: information and trends by cancer type [https://www aihw.gov.au/reports/cancer/cancer-compendium-information-trends-bycancer/report-contents/breast-cancer]

3. Bray FFJ, Soerjomataram I, Siegel RL, Torre LA, Jemal A. Global Cancer Statistics 2018: GLOBOCAN estimates of incidence ad mortality worldwide for 36 cancers in 185 countries. CA Cancer J Clin. 2018:68(6):394 in press.

4. Demark-Wahnefried W, Platz EA, Ligibel JA, Blair CK, Courneya KS, Meyerhardt JA, Ganz PA, Rock CL, Schmitz KH, Wadden T, et al. The role of obesity in cancer survival and recurrence. Cancer Epidemiol Biomark Prev. 2012;21(8):1244-59.

5. Moley KH, Colditz GA. Effects of obesity on hormonally driven cancer in women. Sci Transl Med. 2016;8:323.

6. Ewertz $M$, Jensen M-B. Gunnarsd $\sqrt{ } \geq$ ttir $K n \AA ⿻$, Hل Tjiris I, Jakobsen $E H$, Nielsen $D$, Stenbygaard LE, Tange UB, cold Sr: effect of obesity on prognosis after early-stage breast Cancer. J Clin Oncol. 2011;29(1):25-31.

7. Saquib N, Flatt SW, Natarajan L, Thomson CA, Bardwell WA, Caan B, Rock CL, Pierce JP. Weight gain and recovery of pre-cancer weight after breast cancer treatments: evidence from the women's healthy eating and living (WHEL) study. Breast Cancer Res Treat. 2007:105(2):177-86.

8. Vagenas D, DiSipio T, Battistutta D, Demark-Wahnefried W, Rye S, Bashford J, Pyke C, Saunders C, Hayes SC. Weight and weight change following breast cancer: evidence from a prospective, population-based, breast cancer cohort study. BMC Cancer. 2015:15:28.

9. Chen X, Lu W, Zheng W, Gu K, Chen Z, Zheng Y, Shu XO. Obesity and weight change in relation to breast cancer survival. Breast Cancer Res Treat. 2010;122(3):823-33.

10. Qualtrics: Qualtrics. In. Provo, Utah, USA; 2018.

11. IBM Corp. IBM SPSS statistics for windows. 23rd ed. Armonk, NY: IBM Corp; 2015.

12. StataCorp. Stata Statistical Software Series 13: Release 13. 13th ed. College Station: StataCorp LP; 2013.

13. Barr E, Magliano D, Zimmet P, Polkinghorne K, Atkins R, Dunstan D, Murray S, Shaw J. AusDiab 2005: The Australian Diabetes, Obesity and Lifestyle Study. Melbourne: Tracking the Accelerating Epidemic: Its Causes and Outcomes; 2006

14. Australian Institute of Health and Welfare. Cancer Data in Australia Canberra: Australian Government; 2018.

15. Chen X, Lu W, Gu K, Chen Z, Zheng Y, Zheng W, Shu XO. Weight change and its correlates among breast Cancer survivors. Nutr Cancer. 2011;63(4): 538-48

16. Calle EE, Rodriguez C, Walker-Thurmond K, Thun MJ. Overweight, obesity, and mortality from Cancer in a prospectively studied cohort of U.S. adults. N Engl J Med. 2003;348(17):1625-38.

17. Kroenke $\mathrm{CH}$, Chen WY, Rosner B, Holmes MD. Weight, weight gain, and survival after breast cancer diagnosis. J Clin Oncol. 2005;23(7):1370-8.

18. Nichols HB, Trentham-Dietz A, Egan KM, Titus-Ernstoff L, Holmes MD, Bersch AJ, Holick CN, Hampton JM, Stampfer MJ, Willett WC, et al. Body mass index before and after breast cancer diagnosis: associations with all-cause, breast cancer, and cardiovascular disease mortality. Cancer Epidemiol Biomark Prev. 2009;18(5):1403-9.

19. Makari-Judson G, Braun B, Jerry DJ, Mertens WC. Weight gain following breast cancer diagnosis: implication and proposed mechanisms. World J Clin Oncol. 2014;5(3):272-82.

20. Australian Institute of Health and Welfare. A picture of overweight and obesity in Australia. Canberra: Australian Government; 2017

21. Gandhi A, Copson E, Eccles D, Durcan L, Howell A, Morris J, Howell S, McDiarmid S, Sellers K, Gareth Evans D, et al. Predictors of weight gain in a cohort of premenopausal early breast cancer patients receiving chemotherapy. Breast (Edinburgh, Scotland). 2019;45:1-6.

22. Heideman WH, Russell NS, Gundy C, Rookus MA, Voskuil DW. The frequency, magnitude and timing of post-diagnosis body weight gain in Dutch breast cancer survivors. Eur J Cancer (Oxford, England : 1990). 2009;45(1):119-26.

23. Cormie P, Atkinson M, Bucci L, Cust A, Eakin E, Hayes S, McCarthy S, Murnane A, Patchell S, Adams D. Clinical oncology Society of Australia position statement on exercise in cancer care. Med J Aust. 2018;209(4):184-

24. Connor Gorber S, Tremblay M, Moher D, Gorber B. A comparison of direct vs. self-report measures for assessing height, weight and body mass index: a systematic review. Obes Rev. 2007;8(4):307-26.

25. Irwin ML, McTiernan A, Baumgartner RN, Baumgartner KB, Bernstein L, Gilliland FD, Ballard-Barbash R. Changes in body fat and weight after a breast Cancer diagnosis: influence of demographic, prognostic, and lifestyle factors. J Clin Oncol. 2005:23(4):774-82.

26. Nissen MJ, Shapiro A, Swenson KK. Changes in weight and body composition in women receiving chemotherapy for breast cancer. Clin Breast Cancer. 2011;11(1):52-60.

27. Caan BJ, Kwan ML, Hartzell G, Castillo A, Slattery ML, Sternfeld B, Weltzien E. Pre-diagnosis body mass index, post-diagnosis weight change, and prognosis among women with early stage breast cancer. Cancer Causes Control. 2008;19(10):1319-28.

28. Rose DP, Haffner SM, Baillargeon J. Adiposity, the metabolic syndrome, and breast cancer in African-American and white American women. Endocr Rev. 2007;28(7):763-77

29. Greenlee HA, Crew KD, Mata JM, McKinley PS, Rundle AG, Zhang W, Liao Y, Tsai WY, Hershman DL. A pilot randomized controlled trial of a commercial diet and exercise weight loss program in minority breast cancer survivors. Obesity (Silver Spring, Md). 2013;21(1):65-76

30. Australian Institute of Health and Welfare (AlHW). BreastScreen Australia monitoring report 2019. In: Cancer series, vol. 127. Canberra: Australian Government; 2019.

\section{Publisher's Note}

Springer Nature remains neutral with regard to jurisdictional claims in published maps and institutional affiliations.

Ready to submit your research? Choose BMC and benefit from:

- fast, convenient online submission

- thorough peer review by experienced researchers in your field

- rapid publication on acceptance

- support for research data, including large and complex data types

- gold Open Access which fosters wider collaboration and increased citations

- maximum visibility for your research: over $100 \mathrm{M}$ website views per year

At BMC, research is always in progress.

Learn more biomedcentral.com/submissions 